\title{
A trial of opipramol in the treatment of migraine
}

\author{
HARRY JACOBS \\ From Severalls Hospital, Colchester
}

SUMMARY A double blind trial of opipramol (Insidon) compared with placebo for a group of matched patients suffering from migraine has been carried out. The total number of the migraine attacks in a group of 14 patients on opipramol (as compared with the same patients during a pretreatment period of six weeks) showed a $33 \%$ reduction in the number of attacks experienced during the first six weeks. During a further consecutive six weeks after this on treatment, attacks were further reduced to $49 \%$ as compared with the pretreatment period. In the placebo group there was a $20 \%$ increase in the number of migraine attacks in the first six week treatment period as compared with the base line six weeks on no drugs. In the second consecutive six weeks migraine attacks were $2 \%$ more frequent than in the pretreatment period. These figures indicate that opipramol is a drug with considerable promise and effectiveness in the control of migraine attacks.

Initiation of this trial and the associated study of migraine arose from reports from patients having opipramol (Insidon) for psychiatric conditions that their migraine attacks were abolished while on the drug. The population entering the trial was recruited from the territories of the North East Metropolitan Regional Hospital Board, principally that corresponding to the catchment area of Severalls Hospital, which is the writer's base hospital.

\section{METHODS}

To enter the trial those patients referred by family doctors and others who had been circulated had to conform to the definition that they were suffering from 'periodic attacks of headache unilateral, bilateral, or generalized, which have been occurring over two years with intervening periods of good health and are associated with gastrointestinal, visual, or other sensory disturbance.'

Mainly owing to the stringent criteria used, the total entry group of 59 patients was reduced eventually to a total of 27 , who successfully and correctly conformed to the criteria of the trial, 14 on opipramol (Insidon) and 13 on placebo. Patients were allocated blindly and at random to either opipramol or placebo, half having opipramol and half matching placebo tablets. The pharmacist's record was the only key to which patients were in each trial group; neither doctor nor patient knew this-the trial was 'double blind':

The two treated groups were matched for age and sex. In the males there were two age groups: (1) between 15 and 40 years, and (2) 41 to 65 years of age; while females were divided as pre-menopausal or post-menopausal. The tablets were identical as to shape, colour, and taste. The dosage of tablets was $50 \mathrm{mg}$ thrice daily of opipramol or one placeb tablet thrice daily over a treatment period of 1 i weeks. The trial has been in progress for three and 8 half years. Clinics were held at the Essex Count Hospital, Colchester, every six weeks. The assigno ment of patients was carried out by Mr. K. Frees chief pharmacist to the St. Helena group
hospitals.

In the first interview the patients were given a printed instruction sheet. During the first six week period they were to avoid all drugs for migraine as far as humanely and reasonably practicable. They were given a self-rating chart on which they were to enter every migraine attack. The duration in hours was to be entered on it. Each attack was rated by the patient as mild or severe. Accompaniments such as vomiting, visual upsets, etc., were noted, along with any drugs they did eventually have to take and the effect of the drugs. The women recorded dates of menstruation when applicable.

The patients returned after six weeks when the details on the chart were checked. This six week period provided the base line for comparison with the treatment period. Patients were admitted to the therapeutic trial only after satisfactorily completing 윽 this pre-trial period. Each patient was again given a six week rating card. A clinical assessment interview was carried out.

COMPARABILITY OF THE TWO GROUPS ON TREATMENT Eleven of the 14 patients taking opipramol and 10 of the 13 on placebo were females: four in each group 
were classified as post-menopausal. The ages ranged from 23 to 58 years in the opipramol group (mean $=$ 39.6 years) and from 31 to 67 years in the placebo group (mean $=44 \cdot 4$ years). The patients allocated to opipramol were as a group more severely affected by migraine (in the pretreatment period) than those on placebo. The reasons for the losses from the trial are given in Table 1.

TABLE 1

REASONS FOR LOSSES FROM TRIAL

\begin{tabular}{|c|c|c|}
\hline & Opipramol & Placebo \\
\hline $\begin{array}{ll}\text { Considered for admission } & 59 \\
\text { Not issued with tablets } & 12\end{array}$ & & \\
\hline Tablets issued & 26 & 21 \\
\hline \multirow{6}{*}{$\begin{array}{l}\text { Did not attend after issue of tablets } \\
\text { Withdrawn by GP in view of trade as } \\
\text { bus driver } \\
\text { Admitted as inpatient for migraine } \\
\text { No pretreatment record available } \\
\text { No documents }\end{array}$} & 10 & 5 \\
\hline & & \\
\hline & - & 1 \\
\hline & - & 1 \\
\hline & 1 & - \\
\hline & $1^{*}$ & $1+$ \\
\hline Total losses & 12 & 8 \\
\hline Available for analysis & 14 & 13 \\
\hline
\end{tabular}

* Miss X. + Mrs. Y.

For one patient in each group no record of the second treatment period was available.

\section{RESULTS}

CHANGE IN NUMBER OF ATTACKS The total numbers of attacks (discriminating mild and severe) suffered by each treatment group (A, B, and $C$ ) in the three six week periods are shown in Table 2. It is clear that the number of attacks in the opipramol group declined after the start of treatment, while the number in the placebo group increased.

The 13 patients on opipramol had 73 attacks in the pretreatment period and hence had more opportunity to improve than the 12 on placebo, who between them had 50 attacks in the same period.

PERCENTAGE IMPROVEMENT The progress of the two groups is best shown when the starting level of each is taken as 100 and the number of attacks in the $\mathrm{B}$ and $\mathrm{C}$ periods was expressed proportionately. This has been done in Table 3, from which it is evident that, while in the opipramol group the total attacks were reduced to $67 \%$ of the pretreatment number in the first treatment period and further reduced to $51 \%$ in

TABLE 2

NUMBER OF ATTACKS FOR PATIENTS IN EACH TREATMENT GROUP*

\begin{tabular}{|c|c|c|c|c|c|c|c|c|c|c|}
\hline \multirow[t]{3}{*}{ Treatment } & \multirow[t]{3}{*}{$N$} & \multicolumn{9}{|c|}{ Attacks } \\
\hline & & \multicolumn{3}{|c|}{ Total } & \multicolumn{3}{|c|}{ Mild } & \multicolumn{3}{|c|}{ Severe } \\
\hline & & $A$ & $B$ & $C$ & $A$ & $B$ & C & $A$ & $B$ & C \\
\hline \multicolumn{11}{|c|}{ All who completed three periods } \\
\hline Opipramol & 13 & 73 & 49 & 37 & 48 & 33 & 21 & 25 & 16 & 16 \\
\hline Placebo & 12 & 50 & 60 & 51 & 20 & 24 & 24 & 30 & 36 & 27 \\
\hline \multicolumn{11}{|c|}{ All who completed two periods } \\
\hline $\begin{array}{l}\text { Opipramol } \\
\text { Placebo }\end{array}$ & $\begin{array}{l}14 \\
13\end{array}$ & $\begin{array}{l}79 \\
55\end{array}$ & $\begin{array}{l}51 \\
64\end{array}$ & & $\begin{array}{l}50 \\
20\end{array}$ & $\begin{array}{l}33 \\
24\end{array}$ & & $\begin{array}{l}29 \\
35\end{array}$ & $\begin{array}{l}18 \\
40\end{array}$ & \\
\hline
\end{tabular}

$A=$ pretreatment period. $B=$ first six weeks of treatment. $C=$ second six weeks of treatment.

TABLE 3

ATTACKS IN TREATMENT PERIODS AS PER CENT OF NUMBER IN PRETREATMENT PERIOD

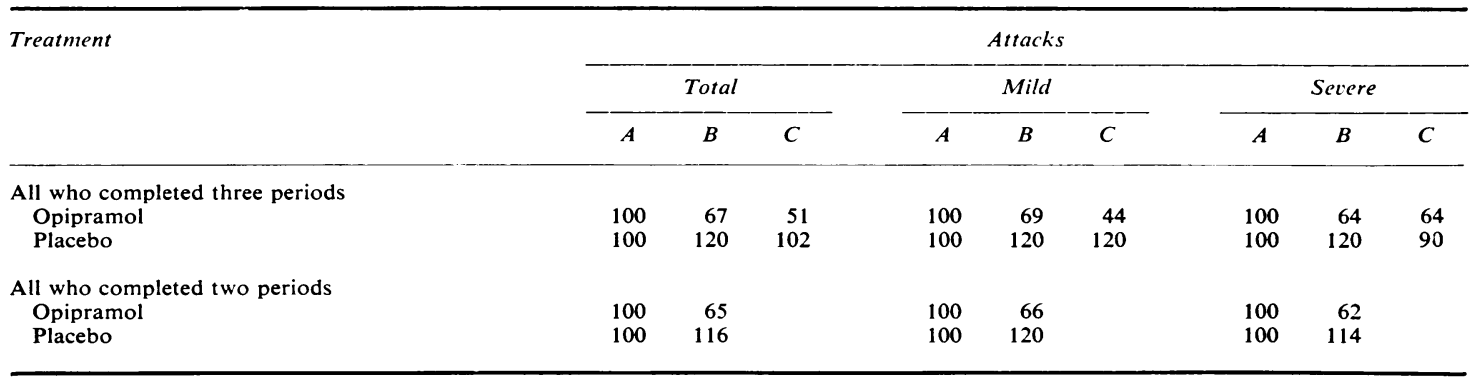


the second period, in the placebo group there was a $20 \%$ increase in the first treatment period and, although this improved somewhat in the second period, attack frequency remained $2 \%$ higher than in the pretreatment period.

The actual improvement in the opipramol group during period B was therefore $33 \%$ of the possible improvement, and in period C $49 \%$ : but in the placebo group there was no improvement-but $20 \%$ deterioration in $\mathrm{B}$, and $2 \%$ in $\mathrm{C}$. Mild attacks followed much the same course in the group on opipramol-the actual improvement, expressed as percent of possible, being $31 \%$ in the $\mathrm{B}$ period and $56 \%$ in the $\mathrm{C}$ period, while the group on placebo showed $20 \%$ deterioration in both $\mathrm{B}$ and $\mathrm{C}$ periods.

Severe attacks also improved $36 \%$ on opipramol in $\mathrm{B}$, but showed no further improvement in the $\mathrm{C}$ period; the group on placebo deteriorated $20 \%$ during $\mathrm{B}$, but showed $10 \%$ improvement on the pretreatment number of attacks in period $C$.

When the one patient in each group who did not complete the second treatment period was added to the data - the results of progress in the $B$ period were unchanged (see lower sections of Tables 2 and 3).

MEAN NUMBER OF ATTACKS PER PATIENT Because of the difference in starting levels, and also for the purpose of carrying out tests of the statistical significance of the differences, the figures of Table 2 were related to the number of patients in the groups to provide the index 'mean number of attacks per patient'. The results are shown in Table 4.

Table 4 indicates that, in the pretreatment period, those on opipramol had on the average two more mild attacks per patient than those on placebo, but about half a severe attack less per patient. Combining mild and severe attacks, those on opipramol had in the pretreatment period, on the average, 1.4 attacks per patient more than those on placebo. The difference in the number of mild attacks was on the borderline of statistical significance (at the $5 \%$ level) but the differences in severe and total attacks were not greater than would be expected from the play of chance.

Little importance attaches to the mean scores in periods $B$ and $C$. They are used to calculate the mean improvement per patient in the experience in the pretreatment period. The results are shown in Table 5.
Table 5 shows that the difference between the opipramol and placebo groups as regards the average amount of improvement per patient bordered on statistical significance for both mild and severe attacks in the first treatment periodthe difference being 1.5 for mild and 1.2 per patient for severe attacks. When mild and severe attacks were combined, the difference in amount of improvement in total attacks ( 2.7 per patient) was significant at the 0.02 level.

In the second treatment period the difference in improvement in mild attacks ( 2.4 per patient) was significant, but not the difference of 0.9 in severe attacks. Combined, however, the difference in improvement in the total number of attacks (2.9) was statistically significant.

Since, except for severe attacks in period $\mathrm{C}$, the opipramol group improved, while the placebo group deteriorated, positive results of the significance tests were perhaps to be expected.

NUMBERS IMPROVED, NO CHANGE, AND WORSE If we ignore the amount of improvement and deterioration, and consider only how mant patients had fewer, the same, or more attacks i⿺辶⿸户⿵冂卄八 the treatment periods compared with their pre $\overline{-}-$ treatment period, Table 6 gives the relevant information. For example: 10 of the 13 op opipramol had fewer attacks (mild and severe in the first period of treatment, one had the same number, and two had more; whereas of the 12 on placebo, four had fewer, two the same number, and six more.

Table 6 shows the number in these categories in the second period, and also discriminates changes in the numbers of mild and severe attacks. With three categories, the numbers were too small for tests of significance of the differences between the distribution of the two treatment groups. All that could be done was to compare the proportions who improved-that is, who had fewer attacks than in the pretreatment period.

It was then found that the proportion of those on opipramol who improved as regards mild attacks in the first treatment period (1 in 1.4) was significantly greater than the proportion of those on placebo who did so ( 1 in 4$)$. In the second period, the difference ( 1 in 1.6 against 1 in 3 ), while still in favour of the opipramol group, did not attain significance level.

Severe attacks showed less difference between the two treatment groups and indeed in the 
TABLE 4

MEAN NUMBER OF ATTACKS PER PATIENT IN EACH PERIOD

\begin{tabular}{|c|c|c|c|c|c|c|c|c|c|c|}
\hline & \multirow[t]{3}{*}{$N$} & \multicolumn{9}{|c|}{ Attacks } \\
\hline & & \multicolumn{3}{|c|}{ Total } & \multicolumn{3}{|c|}{ Mild } & \multicolumn{3}{|c|}{ Severe } \\
\hline & & $A$ & $B$ & $C$ & $A$ & $B$ & $C$ & $A$ & $B$ & $C$ \\
\hline \multicolumn{11}{|c|}{ All who completed three periods } \\
\hline Opipramol & 13 & $5 \cdot 6$ & $3 \cdot 8$ & $2 \cdot 9$ & $3 \cdot 7$ & $2 \cdot 5$ & $1 \cdot 6$ & 1.9 & $1 \cdot 2$ & $1 \cdot 2$ \\
\hline Placebo & 12 & $4 \cdot 2$ & $5 \cdot 0$ & $4 \cdot 2$ & $1 \cdot 7$ & $2 \cdot 0$ & $2 \cdot 0$ & $2 \cdot 5$ & $3 \cdot 0$ & $2 \cdot 2$ \\
\hline Difference & & 1.4 & & & $2 \cdot 0$ & & & -0.6 & & \\
\hline Significance test & & $0.3>$ & $>0 \cdot 2$ & & $0 \cdot 1>$ & $>0 \cdot$ & & $0 \cdot 5>$ & $>0.4$ & \\
\hline \multicolumn{11}{|c|}{ All who completed two periods } \\
\hline Opipramol & 14 & $5 \cdot 6$ & $3 \cdot 6$ & 一 & $3 \cdot 5$ & $2 \cdot 4$ & - & $2 \cdot 1$ & $1 \cdot 3$ & - \\
\hline Placebo & 13 & $4 \cdot 2$ & $4 \cdot 9$ & - & $1 \cdot 5$ & 1.9 & - & $2 \cdot 7$ & $3 \cdot 1$ & 一 \\
\hline Difference & & 1.4 & & & $2 \cdot 0$ & & & -0.6 & & \\
\hline Significance test & & $0.3>$ & $>0.2$ & & $0 \cdot 1>$ & $>0$. & & $0 \cdot 5>$ & $>0.4$ & \\
\hline
\end{tabular}

TABLE 5

MEAN REDUCTION IN NUMBER OF ATTACKS PER PATIENT ON PRETREATMENT PERIOD

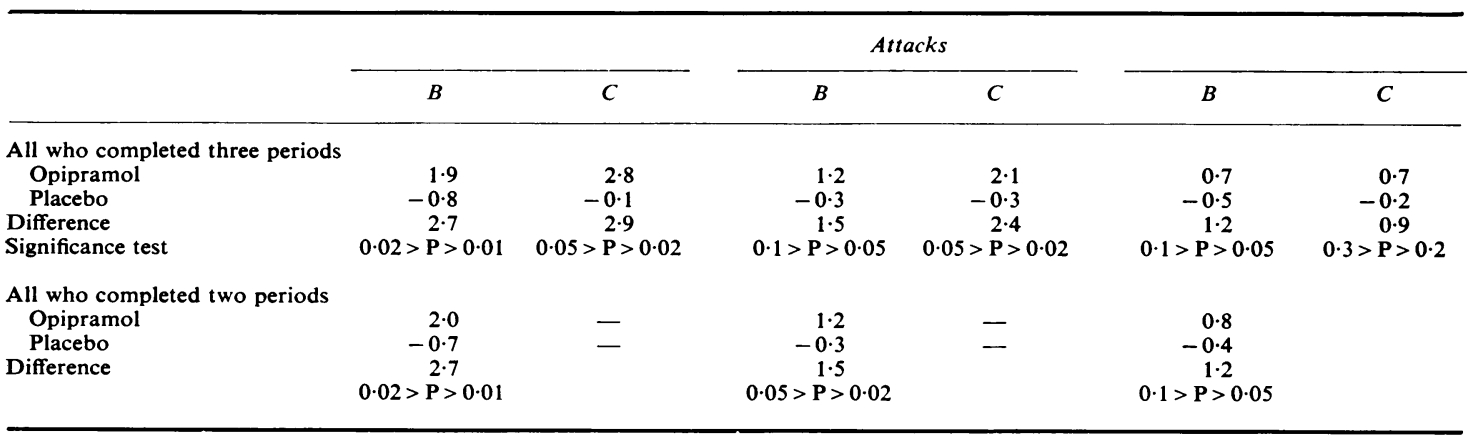

TABLE 6

NUMBER OF PERSONS WITH FEWER, SAME, OR MORE ATTACKS ON TREATMENT THAN IN PRETREATMENT PERIOD*

\begin{tabular}{|c|c|c|c|c|c|c|}
\hline & \multirow[t]{2}{*}{ Total } & \multicolumn{3}{|c|}{ Attacks } & \multirow[t]{2}{*}{ Proportion improved } & \multirow[t]{2}{*}{ Significance test of difference } \\
\hline & & $\begin{array}{l}\text { Improved } \\
\text { (fewer) }\end{array}$ & $\begin{array}{l}\text { No change } \\
\text { (same no.) }\end{array}$ & $\begin{array}{l}\text { Worse } \\
\text { (more) }\end{array}$ & & \\
\hline During 1st treatment period & $\begin{array}{l}\mathbf{O} \\
\mathbf{P}\end{array}$ & $\begin{array}{c}10(11) \\
4(5)\end{array}$ & $\begin{array}{l}1 \\
2\end{array}$ & $\begin{array}{l}2 \\
6\end{array}$ & $\begin{array}{l}1 \text { in } 1 \cdot 3 \\
1 \text { in } 3\end{array}$ & $\mathrm{P}<0.05 \mathrm{~S}$ \\
\hline During 2nd treatment period & $\begin{array}{l}\mathbf{O} \\
\mathbf{P}\end{array}$ & $\begin{array}{l}8 \\
6\end{array}$ & 4 & $\begin{array}{l}1 \\
5\end{array}$ & $\begin{array}{l}1 \text { in } 1 \cdot 6 \\
1 \text { in } 2\end{array}$ & $0.7>\mathrm{P}>0.5$ \\
\hline \multicolumn{7}{|l|}{ Mild attacks } \\
\hline 1st treatment period & $\begin{array}{l}\mathbf{O} \\
\mathbf{P}\end{array}$ & $\begin{array}{l}9(10) \\
3(4)\end{array}$ & $\begin{array}{l}3 \\
6\end{array}$ & $\begin{array}{l}1 \\
3\end{array}$ & $\begin{array}{l}1 \text { in } 1 \cdot 4 \\
1 \text { in } 4\end{array}$ & $\mathrm{P}<0.05 \mathrm{~S}$ \\
\hline 2nd treatment period & $\begin{array}{l}\mathrm{O} \\
\mathrm{P}\end{array}$ & 8 & $\begin{array}{l}2 \\
4\end{array}$ & $\begin{array}{l}3 \\
4\end{array}$ & $\begin{array}{l}1 \text { in } 1 \cdot 6 \\
1 \text { in } 3\end{array}$ & $0.2>P>0.1$ \\
\hline \multicolumn{7}{|l|}{ Severe attacks } \\
\hline 1st treatment period & $\begin{array}{l}\mathbf{O} \\
\mathbf{P}\end{array}$ & $\begin{array}{l}7(8) \\
4(5)\end{array}$ & $\begin{array}{l}4 \\
3\end{array}$ & $\begin{array}{l}2 \\
5\end{array}$ & $\begin{array}{l}1 \text { in } 1 \cdot 9 \\
1 \text { in } 3\end{array}$ & $0 \cdot 5>P>0.3$ \\
\hline 2nd treatment period & $\begin{array}{l}\mathbf{O} \\
\mathbf{P}\end{array}$ & $\begin{array}{l}6 \\
6\end{array}$ & $\begin{array}{l}4 \\
2\end{array}$ & $\begin{array}{l}3 \\
4\end{array}$ & $\begin{array}{l}1 \text { in } 2 \cdot 2 \\
1 \text { in } 2\end{array}$ & $0.9>P>0.8$ \\
\hline
\end{tabular}

* Opipramol $(O)=13$. Placebo $(P)=12$ patients.

Figures in parentheses show the addition of the one patient in each group who completed only the first period of treatment. The difference in proportions improved, and the results of the significance tests were little changed. 
second period, very slightly favoured the placebo group. But when mild and severe attacks were combined, a larger proportion on opipramol improved in the first period ( 1 in $1 \cdot 3$, against 1 in 3) - a statistically significant difference even on these small numbers - but for the second period, the difference failed to attain the critical level.

\section{CONCLUSION}

A double blind trial of opipramol (Insidon) compared with placebo for a group of matched patients suffering from migraine has been carried out. The total number of the migraine attacks in a group of 14 patients on opipramol (as compared with the same patients during a pretreatment period of six weeks) showed a $33 \%$ reduction in the number of attacks experienced during the first six weeks.

During a further consecutive six weeks after this on treatment, attacks were further reduced to $49 \%$ as compared with the pretreatment period. In the placebo group there was a $20 \%$ increase in the number of migraine attacks in the first six week treatment period as compared with the base line six weeks on no drugs.

In the second consecutive six weeks migraine attacks were $2 \%$ higher than in the pretreatment period.

These figures indicate that opipramol (Insidon) is a drug with considerable promise and effectiveness in the control of migraine attacks. The difference in the numbers of attacks was statistically significant even of the relatively small numbers of patients. The difference in improvement was greater as regards mild than severe attacks - particularly in the first period of treatment.

Of those on opipramol 1 in $1 \cdot 3$ showed a reduction in numbers of attacks in the first period, as compared with 1 in 3 of those on placebo. This again was most pronounced as regards mild attacks - for which 1 in 1.4 of those on opipramol as compared with 1 in 4 on placebo, reduced the number of attacks in the first period. In the second period there was less difference between the two treatment groups as $\vec{\circ}$ regards the proportion of patients who improved.

The author wishes to express his warmest thanks for the interest, cooperation, and stimulation of Dr. George Beaumont of Geigy (U.K.) Ltd. and to Geigy is (U.K.) Ltd. for providing financial support for secretarial assistance, without which the projecf or might well have become intolerable; to Mis 8 Gwenyth Jefferies for her most efficient secretarif 옥 assistance throughout; to Dr. Lewis Fanning wh has done the statistical analysis of the trial; to $\mathrm{M}_{\mathbb{R}}^{\bar{R}}$ Kenneth Free, Chief Pharmacist to the St. Helend group of hospitals. 